Article

\title{
Short-Chain Polyglycerol Production via Microwave-Assisted Solventless Glycerol Polymerization Process Over Lioh-Modified Aluminium Pillared Clay Catalyst: Parametric Study
}

\author{
Muhammad Sajid 1,2, Muhammad Ayoub 1,2**(D), Suzana Yusup 1,2, Bawadi Abdullah 1,3(D), \\ Rashid Shamsuddin 1,2 (D), Roil Bilad 1,2 (D), Chi Cheng Chong 1,2 and Aqsha Aqsha 1,2 \\ 1 Chemical Engineering Department, Universiti Teknologi PETRONAS, Seri Iskandar 32610, Malaysia; \\ msajidahmad68@gmail.com (M.S.); drsuzana_yusuf@utp.edu.my (S.Y.); \\ bawadi_abdullah@utp.edu.my (B.A.); mrashids@utp.edu.my (R.S.); mroil.bilad@utp.edu.my (R.B.); \\ chicheng.chong@utp.edu.my (C.C.C.); aqsha@utp.edu.my (A.A.) \\ 2 HiCoE-Center for biofuel and Biochemical Research (CBBR), Institute of Sustainable building, \\ Universiti Teknologi PETRONAS, Seri Iskandar 32610, Malaysia \\ 3 Chemical Engineering Department, Center of Contaminant Control and Utilization (CenCoU), \\ Institute Contaminant Management for Oil and Gas, Bandar Seri Iskandar 32610, Malaysia \\ * Correspondence: muhammad.ayoub@utp.edu.my
}

Received: 2 July 2020; Accepted: 10 August 2020; Published: 3 September 2020

\begin{abstract}
In the current study, microwave-assisted glycerol polymerization for short-chain polyglycerol production was conducted unprecedentedly over low-cost catalyst, lithium-modified aluminium pillared clay (Li/AlPC) catalysts without the solvent. The influences of disparate reaction parameters such as the effects of Li loadings $(10,20,30 \mathrm{wt}$. \%), catalyst loadings $(2,3,4 \mathrm{wt}$. \%), operating temperatures $\left(200,220,240^{\circ} \mathrm{C}\right)$ and operating times $(1-4 \mathrm{~h})$ on the glycerol conversions, and polyglycerol yield (particularly for diglycerol and triglycerol), were elucidated. The fresh catalysts were subjected to physicochemical properties evaluation via characterization techniques, viz. $\mathrm{N}_{2}$ physisorption, $\mathrm{XRD}$, SEM, $\mathrm{NH}_{3}$-TPD and $\mathrm{CO}_{2}$-TPD. In comparison, $20 \mathrm{wt}$ \% Li/AlPC demonstrated the best performance under non-conventional heating, credited to its outstanding textural properties (an increase of basal spacing to $21 \dot{\mathrm{A}}$, high surface area of $95.48 \mathrm{~m}^{2} / \mathrm{g}$, total basicity of $34.48 \mathrm{mmol} / \mathrm{g}$ and average pore diameter of $19.21 \mathrm{~nm}$ ). Within the studied ranges, the highest glycerol conversion $(98.85 \%)$ and polyglycerol yield $(90.46 \%)$ were achieved when catalyst loading of $3 \mathrm{wt}$. \%, reaction temperature of $220^{\circ} \mathrm{C}$ and reaction time of $3 \mathrm{~h}$ were adopted. The results obtained also anticipated the higher energy efficiency of microwave-assisted polymerization than conventional technique $(>8 \mathrm{~h})$, as the reaction time for the former technology was shorter to attain the highest product yield. The study performed could potentially conduce the wise utilization of surplus glycerol generated from the biodiesel industry.
\end{abstract}

Keywords: glycerol polymerization; polyglycerol; aluminium pillared clay; alkali modified; microwave

\section{Introduction}

Petroleum reserves have been stumbling, but the demand for the fuel is growing with time. Therefore, utilization of biomass, which is known as a renewable and sustainable substitute resource, has begun gaining consciousness in the past few decades for biodiesel production to substitute the fossil-fuel-derived diesel. However, biodiesel production was ineluctably accompanied by $10 \mathrm{wt}$. \% of glycerol generation as a side product during the transesterification reaction [1]. Glycerol has been an 
astonishing source to be used as a cheap feedstock in different products' production such as tobacco, detergents, explosives, cellophanes, alkyd resins, etc. [2]. Nevertheless, the traditional exploitation and direct usage of glycerol were unable to cope with its superfluous production, which was then devoted to the indirect conversion of surplus glycerol into price-worthy outputs via polymerization, acetalization, esterification, hydrogenolysis, dehydration, pyrolysis etc. [3-7]. The maximal utilization of the gluts of waste glycerol necessitates a new pathway for better sustainability of biodiesel industry development.

Among them, glycerol polymerization has advantages in its reaction mechanisms for synthesizing oxygenated components, which can be directly used as fuel additives such as polyglycerols and polyglycerol ethers [8] with the presence or absence of solvents. Furthermore, the glycerol polymerization process is uncomplicated and economically feasible, thus making the overall process lucrative. The polyglycerol, also known as glycerol ether mainly made up of di- and tri-glycerol isomers, is worthwhile due to its broad applications in the cosmetics, food, and pharmaceutical industries [9]. To date, glycerol polymerization into polyglycerol has been widely performed under conventional heating with the aid of traditionally used catalysts such as hydrotalcite, mixed oxides, alkaline earth metal oxides, zeolite, and mesoporous material (MCM-41) [10]. The ordered mesoporous catalysts rich in silica or specific microporous crystalline structured catalysts were considered more applicable for the optimized glycerol conversion as compared to the homogeneous catalyst [11]. Regrettably, the use of conventional heterogeneous catalysts, especially zeolites and metal-loaded zeolites, has limitations in terms of selective conversion and activities, especially when large molecules were involved due to the mass transfer restrictions within the microporous solids [12,13]. Additionally, a longer reaction time $(>8 \mathrm{~h})$ and higher energy consumption are needed under conventional heating and even resulted in leaching of the active metals [14].

Owing to the lack of stability, high cost, shrinking, and swelling of the conventional catalysts, the synthesis of the low-cost potential catalytic route remains challenging. With regards to this matter, a vast variety of cheap wastes have been utilized for glycerol polymerization such as waste duck bones, waste coffee grounds, polyethylene terephthalate (PET), and montmorillonite (AlPC) [15-17]. AlPC was preferred as the modified form of AlPC is low-cost, easy and safe to handle and recyclable. In our published work $[18,19]$, the LiOHmodified AlPC catalyst was utilized for glycerol polymerization without solvent under conventional heating and achieved up to $56 \%$ diglycerol selectivity and $98 \%$ glycerol conversion at $240{ }^{\circ} \mathrm{C}$ after $12 \mathrm{~h}$ reaction. It was found that the excellent catalytic performance by AlPC support as a solid base catalyst was owing to the enhanced glycerol oligomerization by its favourable physicochemical properties (increased basic strength and pore size). However, the relatively long reaction time and higher energy consumption of the conventional process urged seeking for an alternative heating method during the reaction.

Microwave polymerization emerged as a newly touted technique that applies microwave as the heat source to minimize the heating time and energy consumption. Previously, Estevez et al. [20] attempted the first-ever microwave-assisted glycerol polymerization with tert-butyl alcohol (solvent), and surprisingly, highest high ethers yield was achieved at $21 \%$ within $15 \mathrm{~min}$ of reaction time only at $85^{\circ} \mathrm{C}$. When using microwave heating, the heat transfer is more efficient as the heat is generated within the core of material by the interaction of microwave with the reactant. As electromagnetic radiation, microwave radiation consists of electric and magnetic fields that are perpendicular to each other. In the electromagnetic spectrum, microwave represents an electromagnetic wave that lies in between the infrared (IR) and the radio-wave regions, with a wavelength range of $0.001-1 \mathrm{~m}$ (refers to $300 \mathrm{MHz}-300 \mathrm{GHz}$ frequency range).

To cope with the surplus of glycerol and to derive the worthwhile compound, innovative, cost-effective and eco-friendly catalytic processes were attempted in this current study. The influences of reaction parameters of lithium-modified aluminium pillared clay (Li/AlPC) catalysts, e.g., Li loadings $(10,20,30 \mathrm{wt} . \%)$, catalyst loading $(2,3,4 \mathrm{wt} . \%)$, operating temperature $\left(200,220,240{ }^{\circ} \mathrm{C}\right)$ and operating time $(1-4 \mathrm{~h})$ over microwave-assisted solvent-free glycerol polymerization, were elucidated. The Li/AlPC catalyst possesses a unique pillared-layered structure, tunable interlayer spacing and high 
thermal stability that enhanced the overall desired products yield in a shorter time-on-stream for the current study.

\section{Materials and Method}

\subsection{Materials}

Pure glycerol with the highest purity (>99\%) was purchased from Merck Sdn Bhd, Malaysia. Montmorillonite K-10 clay, lithium hydroxide ( $\mathrm{LiOH}, 99.99 \%)$, diglycerol (>80\%) and triglycerol (>70\%, HPLC grade) were purchased from Sigma-Aldrich Sdn Bhd, Malaysia. Diglycerol and triglycerol were used as high-performance liquid chromatography (HPLC) standards. No further treatment was performed on these chemicals before their usage.

\subsection{Preparation of Li/AlPC Catalyst}

The pillared AlPC formation in interlamellar space was synthesized by following the methodology proposed by Gil et al. [21]. Firstly, a $250 \mathrm{~mL}$ round-bottom flask furbished with a reflux condenser was loaded with 10, 20, and $30 \mathrm{wt}$. \% LiOH and $10 \mathrm{~g}$ of Montmorillonite K-10 clay, followed by $100 \mathrm{~mL}$ of deionized water addition. This mixture was heated to $50{ }^{\circ} \mathrm{C}$ and stirred vigorously for $12 \mathrm{~h}$ to achieve maximum cations intercalation in the clay. The slurry was then left for cooling to ambient temperature, and then the solid was isolated out by filtration and centrifugation and rinsed with deionized water. These procedures were performed $>2$ times to eliminate all the possible soluble species from the solid. The alkali modified clay obtained was then air-dried at $110{ }^{\circ} \mathrm{C}$ for $12 \mathrm{~h}$ and calcined at $600{ }^{\circ} \mathrm{C}$ (ramping rate, $5^{\circ} \mathrm{C} / \mathrm{min}$ ) for $4 \mathrm{~h}$ to obtain the final catalysts. These catalysts were designated as $x$ wt. \%Li/AlPC, where $x$ stands for the Li loadings. The physicochemical attributes of the as-synthesized fresh catalysts were investigated via $\mathrm{N}_{2}$ adsorption-desorption analysis, $\mathrm{XRD}, \mathrm{SEM}, \mathrm{NH}_{3}-\mathrm{TPD}$ and $\mathrm{CO}_{2}-\mathrm{TPD}$.

\subsection{Catalyst Characterization}

$\mathrm{N}_{2}$ adsorption-desorption analysis was conducted in a Micromeritics ASAP 2020 (Centre of Analatical Lab, university Teknologi, PETRONAS, Malaysia)instrument to ascertain the surface area, pore volume and pore size of the catalysts. Before the analysis, $0.1 \mathrm{~g}$ of the samples were degassed under inert $\mathrm{N}_{2}$ flow at $300{ }^{\circ} \mathrm{C}$ to remove moisture and other adsorbed impurities. Subsequently, $\mathrm{N}_{2}$ physisorption analyses were conducted at $-196^{\circ} \mathrm{C}$ by using $\mathrm{N}_{2}$ as the adsorbate. The surface area was computed according to the standardized Brunauer-Emmett-Teller (BET) method, while the pore diameter distributions and volume were estimated based on the desorption isotherms by using the Barrett-Joyner-Halenda (BJH) method.

X-ray diffraction (XRD) analysis was performed in a Philips X'pert MPD (Centre of Analatical Lab, university Teknologi, PETRONAS, Malaysia)diffractometer to investigate the crystallographic structure of the catalysts. The analyses were performed at room temperature using $\mathrm{Cu} \mathrm{K} \alpha$ radiation $(\lambda=1.5405 \AA)$ at $40 \mathrm{kV}$ and $30 \mathrm{~mA}$. The XRD pattern was recorded in the scanning range $2 \theta=1^{\circ}-85^{\circ}$, step size $=0.01^{\circ}$. The crystallite phases present over the catalysts were matched with the Joint Committee on Powder Diffraction Standards (JCPDS) files.

The acidity and basicity nature of the prepared catalysts were characterized by $\mathrm{NH}_{3}-\mathrm{TPD}$ and $\mathrm{CO}_{2}$-TPD, respectively, by using Thermo Scientific TPDRO 1100 equipment(Centre of Analatical Lab, university Teknologi, PETRONAS, Malaysia). Firstly, $0.5 \mathrm{~g}$ of the catalysts was heated under $25 \mathrm{~mL} / \mathrm{min}$ Helium gas flows in a micro-quartz U-tube at $100{ }^{\circ} \mathrm{C}$ for $2 \mathrm{~h}$. After that, the samples were cooled down until $40{ }^{\circ} \mathrm{C}$ and then purged with the gas containing 7 vol. $\%$ of $\mathrm{NH}_{3}, \mathrm{CO}_{2} / \mathrm{He}$ gas $(25 \mathrm{~mL} / \mathrm{min})$ for $1 \mathrm{~h}$ at $100{ }^{\circ} \mathrm{C}$ for adsorption process. The desorption process was carried out by purging He flow for $30 \mathrm{~min}$. The catalysts were then heated from 100 to $800{ }^{\circ} \mathrm{C}$ (ramping rate: $10^{\circ} \mathrm{C} / \mathrm{min}$ ). Eventually, the desorption signals within 100 and $900^{\circ} \mathrm{C}$ were analyzed by a TCD detector(Centre of Analatical Lab, university Teknologi, PETRONAS, Malaysia). SEM analyses were performed using Zeiss Supra 35 VP instrument (Centre of Analatical Lab, university Teknologi, PETRONAS, Malaysia )operated 
at $3 \mathrm{kV}$ to observe the morphology changes of the catalysts upon modified by LiOH. The samples were immobilized on black carbon conductive tape and then sputter-coated with platinum before the observation.

Thermal gravimetric analysis (TGA) was performed on spent catalysts to compare their fraction of volatile components by monitoring the weight change using TGA Q500 unit, TA Instruments(Centre of Biomass and Biofuel (CBBR), Universiti Teknologi, PETRONAS, Malaysia). Approximately $0.1 \mathrm{~g}$ of the spent catalysts were evacuated under inert $\mathrm{N}_{2}$ flow to remove the possible adsorbed impurities. The samples were then heated from 25 to $900{ }^{\circ} \mathrm{C}$ (ramping rate: $10{ }^{\circ} \mathrm{C} / \mathrm{min}$ ) under $100 \mathrm{~mL} / \mathrm{min}$ airflow $\left(20 \% \mathrm{O}_{2} / 80 \% \mathrm{~N}_{2}\right)$.

\subsection{Glycerol Polymerization Reaction}

The glycerol polymerization reaction was executed in a closed-batch system (pressure-controlled) under continuous stirring, where $250 \mathrm{~mL}$ three-necked round bottom flask reactor was used and heated by microwave irradiation (Dixson, model DX10116, Centre of Biomass and Biofuel (CBBR), Universiti Teknologi, PETRONAS, Malaysia). As illustrated in Figure 1, the three-necked round bottom flask was placed inside a modified version microwave oven and connected to a reflux condenser, proportional integral derivative (PID) temperature controller and $\mathrm{N}_{2}$ gas supply. The reaction mixture was irradiated until the desired temperature, which was manipulated by the power-controlled oven. The reaction was performed under ambient pressure with the absence of solvents. During the reaction, finite amounts of Li/AlPC catalysts were added into $50 \mathrm{~g}$ of glycerol and inert $\mathrm{N}_{2}$ gas was supplied continuously under ambient pressure to avoid air stagnation that can result in glycerol oxidization and carbonization [22]. The four parameters studied were Li loadings on AlPC (10, 20 and 30 wt. \%), reaction temperature $\left(200,220\right.$ and $\left.240{ }^{\circ} \mathrm{C}\right)$, catalyst loadings $(2,3$ and $4 \mathrm{wt}$. \%), and reaction time $(1,2$, 3 and $4 \mathrm{~h}$ ). The reaction temperature range was chosen as the selected temperatures were verified to be able to transform glycerol into polyglycerol sufficiently and suppress the formation of undesired products [18].

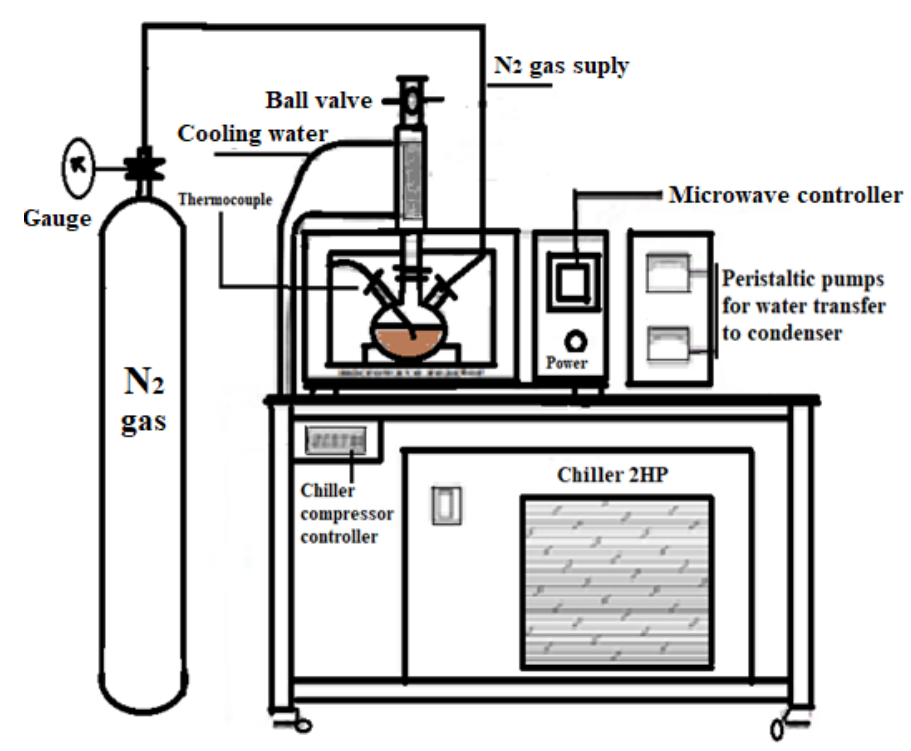

Figure 1. Reactor set up for glycerol polymerization reaction.

Samples were taken out every $1 \mathrm{~h}$ of the reaction and subsequently analyzed. The polymerization product yield (polyglycerol, diglycerol, triglycerol) along the reaction time were analyzed using Shimadzu HPLC (Centre of Biomass and Biofuel (CBBR), Universiti Teknologi, PETRONAS, Malaysia) equipped with a $250 \times 4.6 \mathrm{~mm}, 5 \mu \mathrm{m}$ Hypersil Gold Amino HPLC column and Shimadzu RID 10-A detector (Centre of Biomass and Biofuel (CBBR), Universiti Teknologi, PETRONAS, Malaysia). 
The analysis program was heating from 60 to $240{ }^{\circ} \mathrm{C}$ (ramping rate: $20^{\circ} \mathrm{C} / \mathrm{min}$ ) with an analysis time of $25 \mathrm{~min}$. The glycerol conversion and products yields were computed by the following equations:

$$
\begin{gathered}
\text { Glycerol conversion }(\%)=\frac{\text { moles of glycerol reacted }}{\text { moles of glycerol taken }} \times 100 \% \\
\text { Polyglycerol yield }(\%)=\frac{\text { moles of polyglycerol produced }}{\text { moles of glycerol taken }} \times 100 \% \\
\text { Diglycerol yield }(\%)=\frac{\text { moles of diglycerol produced }}{\text { moles of glycerol taken }} \times 100 \% \\
\text { Triglycerol yield }(\%)=\frac{\text { moles of triglycerol produced }}{\text { moles of glycerol taken }} \times 100 \%
\end{gathered}
$$

Long-chain polyglycerol yield $(\%)=$ Polyglycerol yield - diglycerol yield - triglycerol yield

\section{Results and Discussion}

\subsection{Fresh Catalyst Characterisation}

\subsubsection{BET Analysis}

The physical properties (i.e., surface area, pore diameter and pore volume) of the prepared catalysts are shown in Table 1. The unmodified and modified AlPC catalysts showed considerable differences in terms of their physical attributes, indicating the structural alternation by dealumination upon potent alkali treatment by $\mathrm{LiOH}$ [23]. Unmodified AlPC possesses the highest BET surface area of $230 \mathrm{~m}^{2} / \mathrm{g}$, attributed to the presence of pillared structure as well as hydrated exchangeable cations [18]. Indeed, the surface area of AlPC not only contributed by the porosity over the surface of pillared clay but also within the pillared clay. However, the BET surface area was significantly decreased with the increase in Li loadings from $10 \mathrm{wt}$. \% to $30 \mathrm{wt}$. \%, and the smallest surface area was shown by 30 wt. \%Li/AlPC (11.33 $\left.\mathrm{m}^{2} / \mathrm{g}\right)$. The significant decrease in the surface area of the LiOH-modified AlPC indicated the successful metal dispersion that fills the active pores in the parent AlPC [24]. After the $\mathrm{LiOH}$ intercalation modification, there was probably a certain extent of pores collapse and blockage over the layered structure of AlPC [25]. The smallest surface area demonstrated by $30 \mathrm{wt}$. \%Li/AlPC can be explained by the excessive Li doping on AlPC, which agglomerated and covered the pores to a great extent [26]. Meanwhile, the pore diameter of these modified clay showed an opposite trend, suggesting the pores' expansion, AlPC's wall contraction and changes in basal spacing after the introduction of Li. Intriguingly, the pore volume of $20 \mathrm{wt}$. \%Li/AlPC was the highest compared to other catalysts at $0.309 \mathrm{~cm}^{3} / \mathrm{g}$, suggesting the optimal Li loading to increase the pore volume of parent AlPC. Severe metal agglomeration was confirmed for $30 \mathrm{wt}$ \%Li/AlPC, when it demonstrated the least pore volume, which was even less than that of unmodified AlPC.

Table 1. Textural properties of the synthesis catalyst.

\begin{tabular}{cccc}
\hline Sample & Surface Area $\left(\mathbf{m}^{\mathbf{2}} \mathbf{g}\right)$ & Pore Diameter $(\mathbf{n m})$ & Pore Volume $\left(\mathbf{c m}^{\mathbf{3}} / \mathbf{g}\right)$ \\
\hline AlPC & 230 & 4.106 & 0.236 \\
10 wt. \%Li/AlPC & 163.85 & 16.32 & 0.295 \\
20 wt. \%Li/AlPC & 95.48 & 19.21 & 0.309 \\
30 wt. \%Li/AlPC & 11.33 & 35.14 & 0.108 \\
\hline
\end{tabular}

\subsection{2. $\mathrm{N}_{2}$ Adsorption-Desorption Analysis}

Figure 2A demonstrates the $\mathrm{N}_{2}$ physisorption patterns for parent AlPC and Li-based AlPC catalysts. As illustrated, all the catalysts exhibited the same type IV isotherm, corresponding to the mesoporous material with pore condensation together with hysteresis behaviour between the 
adsorption and the desorption branches according to International Union of Pure and Applied Chemistry (IUPAC) classification [24-27]. The loops are also related to the capillary condensation after monolayer-multilayer adsorption, where the plateau at high relative pressure expresses complete pore filling [28]. However, the bare AlPC catalyst (H4 hysteresis) showed a different hysteresis loop as compared to other modified AIPC (H3 hysteresis). The finding indicated the microporosity of the bare AlPC material, whilst the presence of slit-shaped pores of the Li/AlPC arose from the agglomeration of plate-like particles [24-27]. As stated by Krupskaya et al. [29], a decrease in the steepness of the loop can be explained by a decrease in the pore volume of the sample and the appearance of macro-porosity. The steepnesses of the hysteresis loops were increased with the trend of 30 wt. $\% \mathrm{Li}<$ AlPC $<20$ wt. $\% \mathrm{Li}<10$ wt. \% Li, where the 30 wt. \%Li/AlPC demonstrated the least pore volume, and the result was in line with the BET result (Table 1). Moreover, the H4-type hysteresis loop for $30 \mathrm{wt}$. \%Li/AlPC catalyst was comparably small, suggesting the partially structural disruption of AlPC at highest Li loadings by metal agglomeration over the AlPC [26].
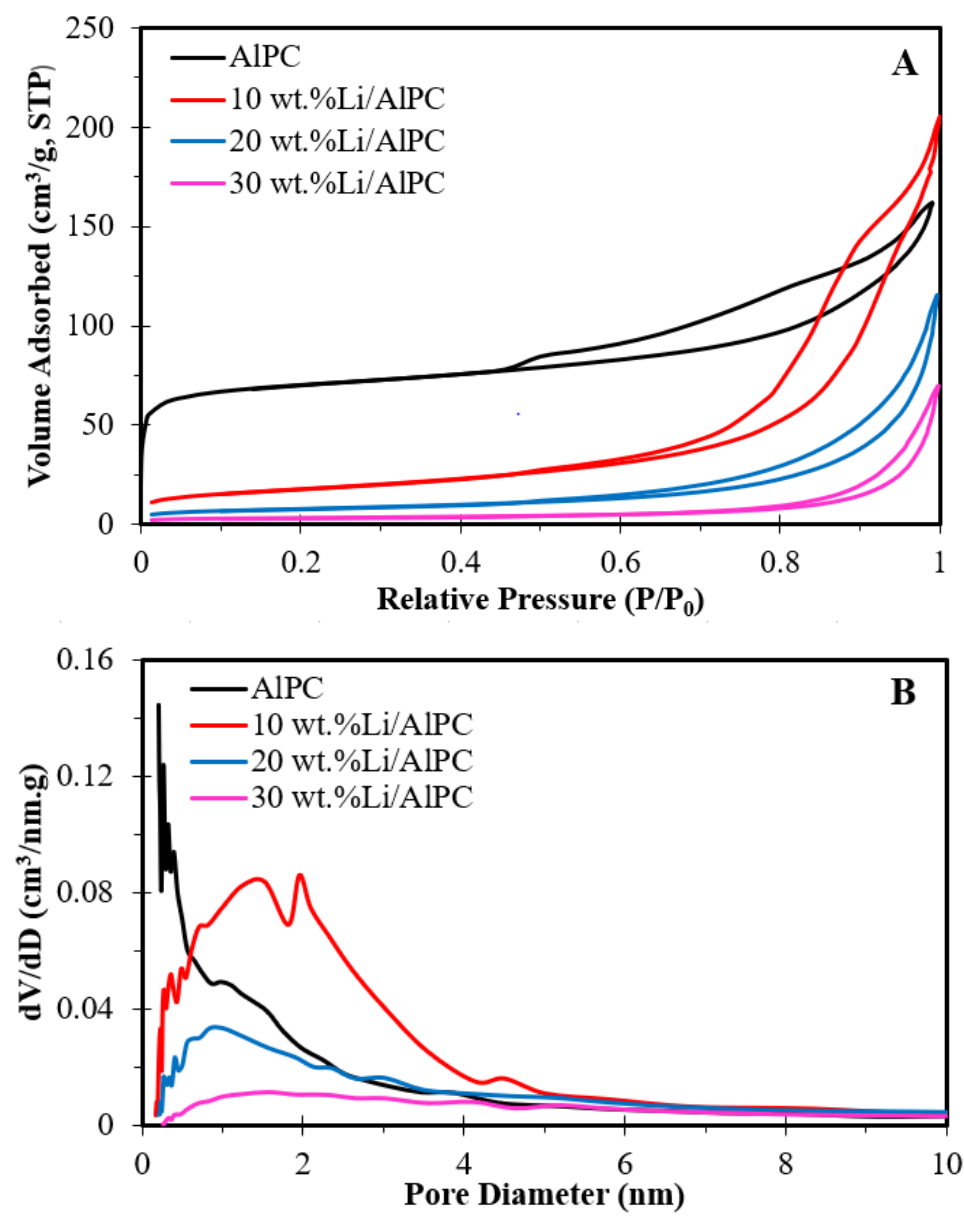

Figure 2. (A) Nitrogen adsorption-desorption isotherms and (B) pore size distribution of AlPC and $x$ wt. \%Li/AlPC ( $x=10,20$ and 30 wt. \%) catalysts.

Figure $2 \mathrm{~B}$ shows the $\mathrm{BJH}$ adsorption pore size distribution curves of the catalysts. As illustrated, AlPC demonstrated a broad multimodal pattern scattered from 0.5 to $6 \mathrm{~nm}$, which was mainly at microporous pore size region $(\leq 2 \mathrm{~nm})$. After loaded with $10 \mathrm{wt}$. $\% \mathrm{Li}$, the pore size gradually shifted to larger pore size, with the majority of pores being between 2 and $4 \mathrm{~nm}$. As the Li loadings increased, the volume of the pore at the microporous region was lower due to the successful incorporation of $\mathrm{Li}$ into the AlPC catalytic supports. 


\subsubsection{XRD Analysis}

XRD spectra of the parent AlPC and $x$ wt. \%Li/AlPC ( $x=10,20$ and 30 wt. \%) catalysts are illustrated in Figure 3. The $d$ (001) reflection of parent AlPC appeared at $2 \theta=1.5^{\circ}$ and corresponds to the $d$ spacing value of $18 \dot{\mathrm{A}}$, and it also depicted the successful pillaring process and microporosity formation of the catalyst. This peak had shifted to $2 \theta=2^{\circ}$ for 10 and $20 \mathrm{wt}$. \% LiOH modified AlPC catalysts, correspond to the interlayer spacing of $21 \dot{A}$ spacing. However, the peak was shifted right to $2 \theta=1.25^{\circ}$ for $30 \mathrm{wt}$. \%Li/AlPC, represented the decrement of decrease of $d$ (001) spacing to $14 \dot{\mathrm{A}}$ as a result of the pillared structure destruction by the high intercalated Li loading [30]. This remarkable increase of $d$ spacing values for both 10 and $20 \mathrm{wt}$. \% Li/AlPC catalysts were attributed to their better dispersion of the highly alkaline Li metal and better swelling ability of the AlPC clay due to its cation exchange capacity. Additionally, AlPC consists predominantly of montmorillonite $2 \theta=20^{\circ}, 22^{\circ}, 34^{\circ}, 61^{\circ}$ [31], and the sharp peaks at $2 \theta=18^{\circ}$ showed the resemblance of smectite [32]. Ten and $20 \mathrm{wt}$. \%Li/AlPC catalysts retained their pristine pillared structure with well-preserved sharp diffraction peak even after Li impregnation, suggesting the non-altered crystallinity of the parent AIPC. There are some new peaks $(\Delta)$ detected in the XRD pattern of the fresh $30 \mathrm{wt}$. \%Li/AlPC, which are ascribed to Li species as stated by previous literature. The absence of the Li species detected for 10 and $20 \mathrm{wt}$ \% \% Li/AlPC implied the successful embedment of Li into the parent AlPC material through the impregnation method.

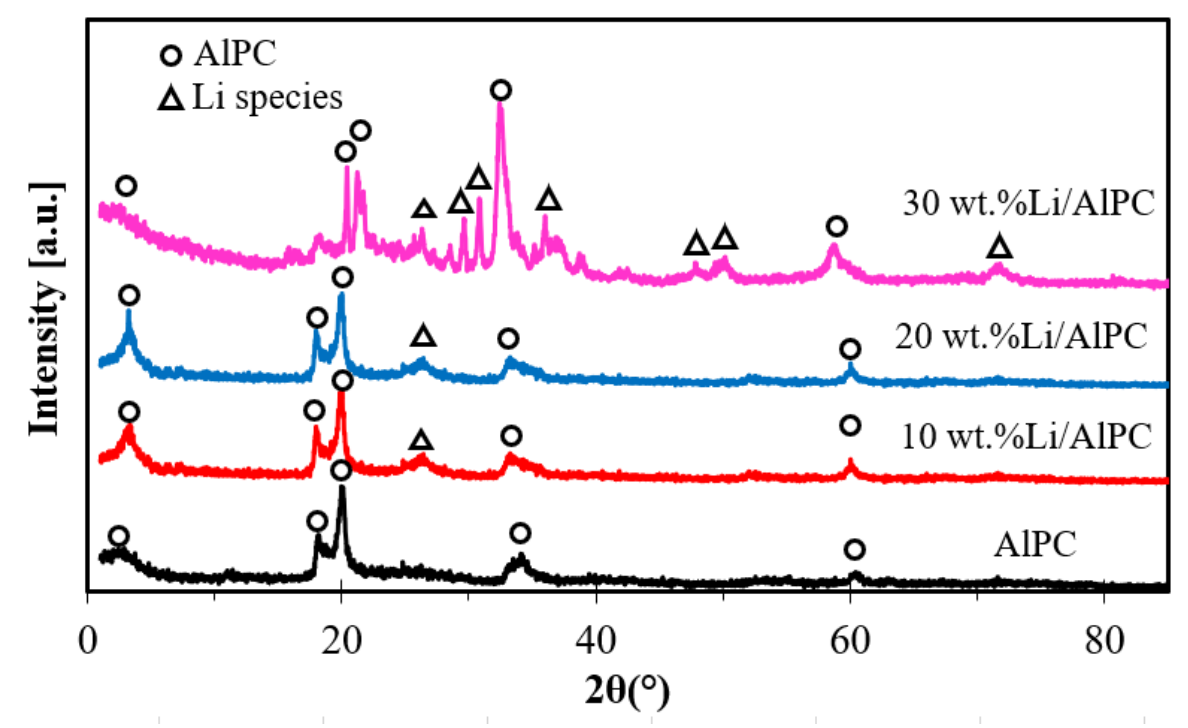

Figure 3. XRD patterns of AlPC and $x$ wt. \%Li/AlPC ( $x=10,20$ and 30 wt. \%) catalysts.

\subsubsection{SEM Analysis}

SEM images of AlPC with various metal loadings are illustrated in Figure 4. As shown in Figure 4A, unmodified AlPC was observed in the form of lamellar morphology with corn-flake-like crystals, with a composition similar to the 2:1 phyllosilicate, which corresponds to mica phase. As shown in Figure 4B-D, even though the pristine morphologies were not altered, the surface textures of $\mathrm{LiOH}$-modified AlPC catalysts were rougher with aggregative appearance. Besides, the modified AlPC indeed appeared in the form of fluffy type material after intercalated with Li. The massive fluffy material observed for $30 \mathrm{wt}$. \% Li/AlPC can be explained by structure transformation into flocked by the excessive metal loading. 

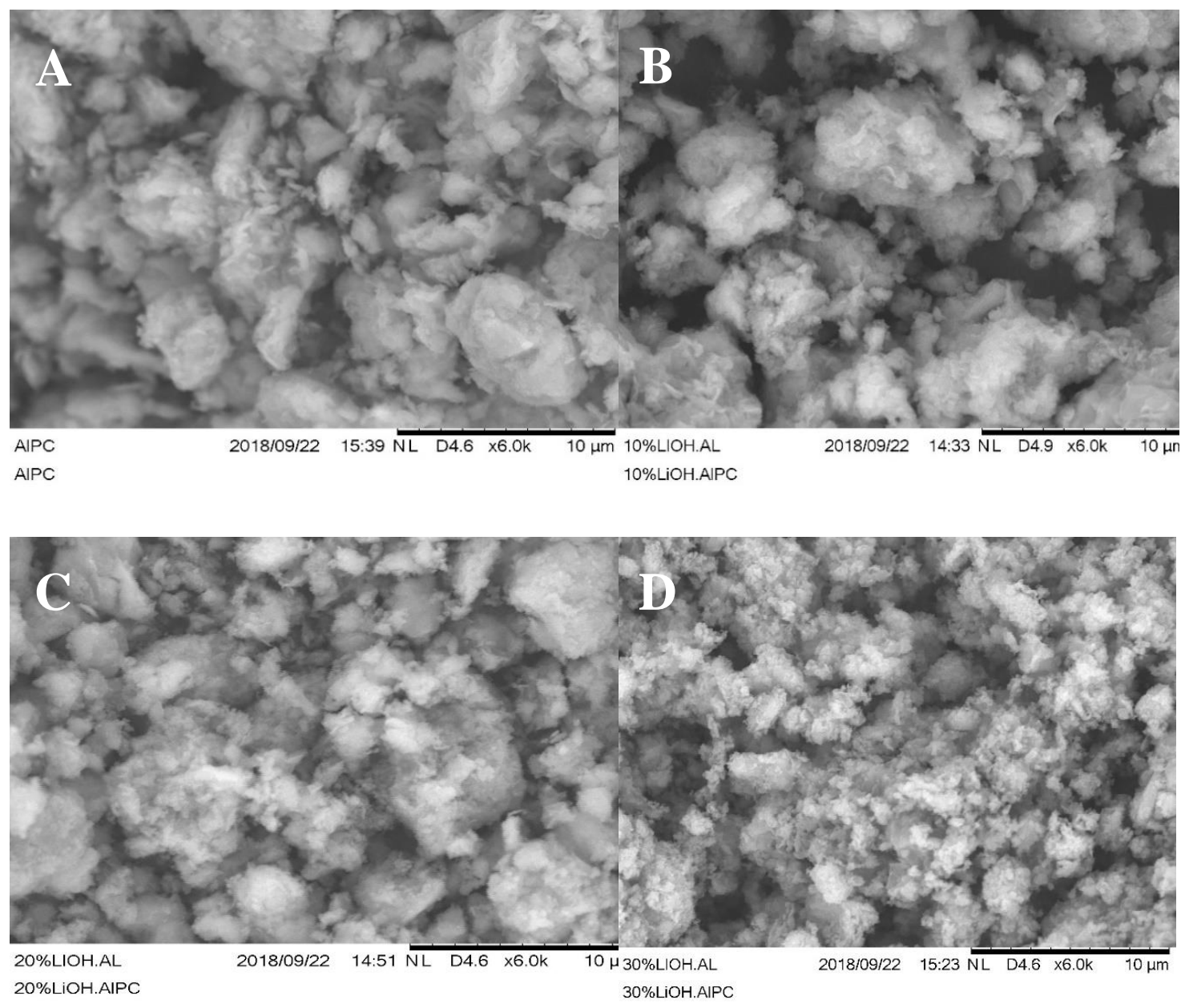

Figure 4. SEM images of (A) AlPC, (B) 10 wt. \% Li/AlPC (C), 20 wt. \% Li/AlPC and (D) 30 wt. \% Li/AlPC catalysts.

\subsection{5. $\mathrm{NH}_{3}$-TPD Analysis}

$\mathrm{NH}_{3}$-TPD was used to evaluate the acidic properties of the prepared catalysts. A series of $\mathrm{NH}_{3}$-TPD curves for unmodified and modified AlPC catalysts with different Li loadings are presented in Figure 5. The unmodified AlPC did not show any obvious curve, but two notable desorption peaks with different intensities can be observed after it was modified by $\mathrm{LiOH}$. The results obtained indicate the ion exchange within AlPC after $\mathrm{LiOH}$ addition induced significant changes in the acidic character of the catalysts. The first desorption peaks detected at around $200-350{ }^{\circ} \mathrm{C}$ indicate the catalyst possesses weak-strength acid sites (unsaturation of $\mathrm{Al}^{3+}$ and $\mathrm{Mg}^{2+}$ ) as a result from the interlayer water $\left(\mathrm{H}_{3} \mathrm{O}^{+}\right), \mathrm{Si}-\mathrm{OH}$ and $\mathrm{Al}-\mathrm{OH}-\mathrm{H}$. The medium-strength acid sites were marked at the $350-550{ }^{\circ} \mathrm{C}$ region, generated by unsaturated $\mathrm{Al}^{3+}$ ions in the octahedral sheets (represented as $\mathrm{Al}_{\mathrm{L}}$ ) and interlayer water. Desorption peaks detected at temperature $>550{ }^{\circ} \mathrm{C}$ were referred to the strong-strength acid sites [33]. The interlayer polarised water primely generates the montmorillonite clay acidity, $\mathrm{Si}-\mathrm{OH}$, $\mathrm{H}_{3} \mathrm{O}^{+}$adsorbed by negatively charged tetrahedral $\mathrm{AlO}_{4}$ (Bronsted acid sites) as well as unsaturated $\mathrm{Al}^{3+}$ ions that belong to Lewis acid sites [30]. For the case of $10 \mathrm{wt}$. \%/AlPC, a relatively higher peak appeared at around $260^{\circ} \mathrm{C}$, and a lower peak was detected at medium-strength and strong acid sites. This finding can be explained by the decrement in the interlayer water and transformation of $\mathrm{Al}-\mathrm{OH}-\mathrm{H}$ to the $\mathrm{Al}_{\mathrm{L}}$ due to dehydration after $10 \mathrm{wt}$. \% Li loading. As the Li loadings increased from $10 \mathrm{wt}$. \% to $30 \mathrm{wt}$. \%, the desorption peaks at lower acid sites gradually shifted towards moderate and strong-strength acid sites. The desorption peaks at the weak acid site were the least obvious for $20 \mathrm{wt}$. \% Li but most intense for its moderate and strong acid sites peak. This result demonstrated 
the highest tendency of $20 \mathrm{wt}$. \% Li loading in enhancing the strong acid sites of AlPC. The total acidities of the catalysts were also computed based on the total area under the curves as shown in Table 2, where the lowest and highest acidity were marked by unmodified AlPC $(0.059 \mathrm{mmol} / \mathrm{g})$ and 20 wt. \% Li/AlPC (2.35 mmol/g), respectively. However, the overall acidity for all the catalysts were considered low as LiOH used is a strong alkali.

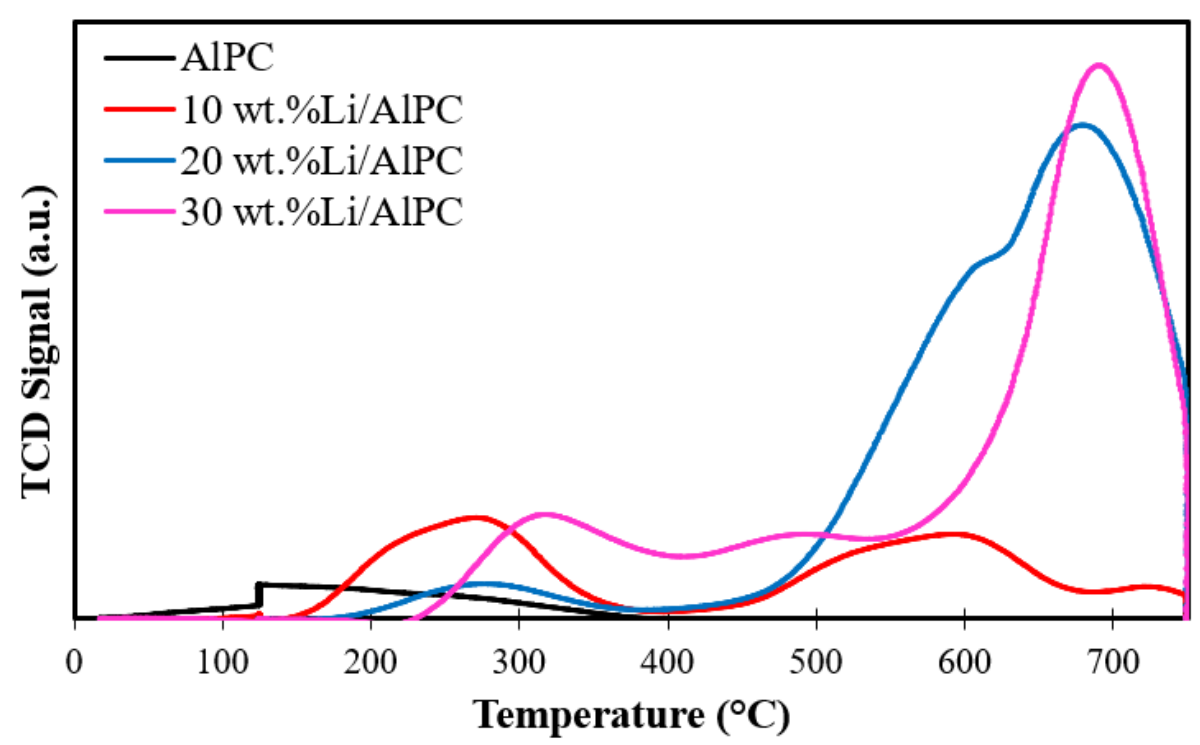

Figure 5. $\mathrm{NH}_{3}$-TPD profiles of AlPC and $x$ wt. \%Li/AlPC $(x=10,20$, and $30 \mathrm{wt}$ \%) catalysts.

Table 2. The total concentration of acidity and basicity in calcined Li/AlPC sample.

\begin{tabular}{ccc}
\hline Sample & Acidity (mmol/g) & Basicity (mmol/g) \\
\hline AlPC & 0.059 & 0.005 \\
$10 \% \mathrm{Li} / \mathrm{AlPC}$ & 0.48 & 12.67 \\
$20 \% \mathrm{Li} / \mathrm{AlPC}$ & 2.35 & 34.48 \\
$30 \% \mathrm{Li} / \mathrm{AlPC}$ & 2.17 & 45.48 \\
\hline
\end{tabular}

\subsection{6. $\mathrm{CO}_{2}$-TPD Analysis}

The basicity evaluation by $\mathrm{CO}_{2}$-TPD of the bare AlPC and AlPC loaded with various Li loadings (10-30 wt. \%) are shown in Figure 6. The basicity follows the inverse trend to the acidity. The desorption peaks detected at the regions $100-350{ }^{\circ} \mathrm{C}, 350-550{ }^{\circ} \mathrm{C}$ and $550-750{ }^{\circ} \mathrm{C}$ were assigned to weak, moderate and strong basic sites, respectively. For bare AlPC, no peak was detected along with the temperature range, evidencing the non-basic nature of parent AlPC. After Li introduction, several peaks were detected in the different region regardless of the Li loadings, suggesting the vital role of $\mathrm{LiOH}$ in improving the basicity of AlPC. As illustrated in Figure 6, the first intense peak was centred at $240{ }^{\circ} \mathrm{C}$, while the second one was centred at $650{ }^{\circ} \mathrm{C}$ for $10 \mathrm{wt} . \% \mathrm{Li}$, expressing the emergence of weak and strong basic sites. Apart from weak and strong basic sites, an extra peak which designated for the moderate basic site was observed at around $480{ }^{\circ} \mathrm{C}$ for $20 \mathrm{wt}$. \% Li loading. For $30 \mathrm{wt}$. \% Li/AlPC, the $\mathrm{CO}_{2}$ desorption peaks detected were of far higher intensities than other catalysts, indicating its highest basicity. From Table 2, it was noted that the overall rate of $\mathrm{CO}_{2}$ desorption was higher than $\mathrm{NH}_{3}$, proving the stronger propensity of Li metal in improving basicity than acidity for AlPC as $\mathrm{LiOH}$ is a strong alkali. The highest basicity was marked by $30 \mathrm{wt}$. \% Li/AlPC with $45.48 \mathrm{mmol}$ of $\mathrm{CO}_{2}$ desorbed/g AlPC, followed by $20 \mathrm{wt}$ \% Li/AlPC (34.38 mmol/g) and $10 \mathrm{wt}$ \% Li/AlPC (12.67 mmol/g). The non-basic nature of bare AlPC was also proven when only $0.005 \mathrm{mmol}$ of $\mathrm{CO}_{2}$ desorbed/g AlPC was detected and can be neglected. 


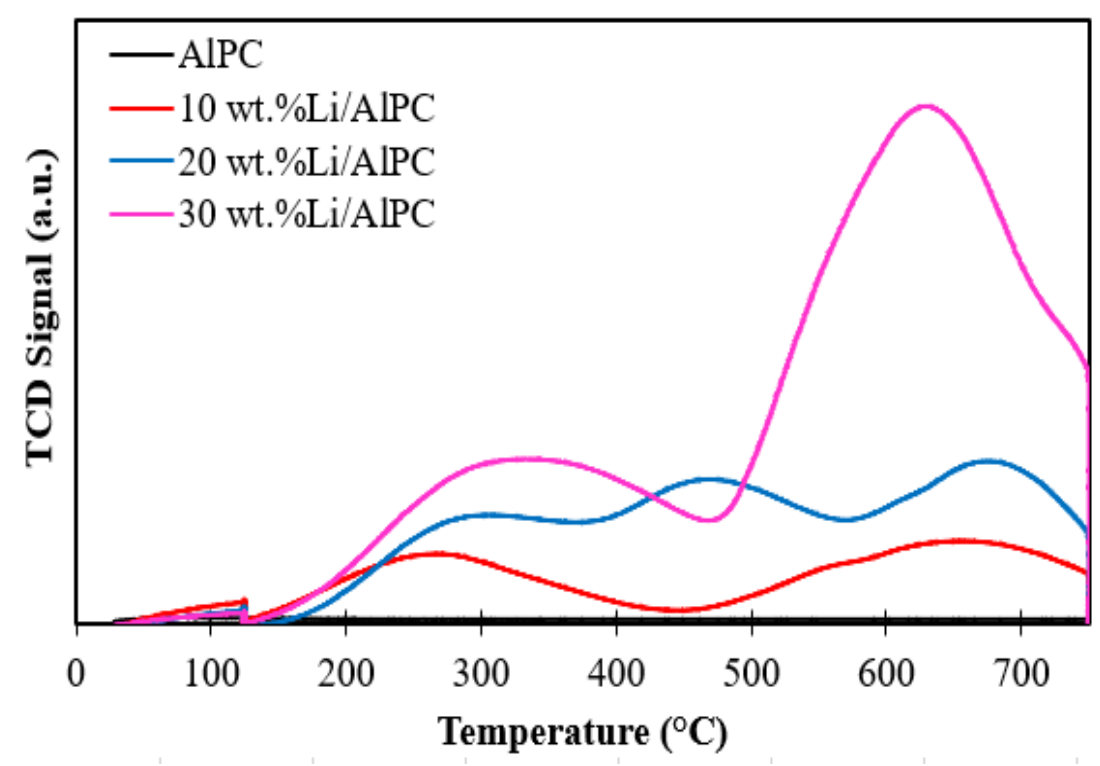

Figure 6. $\mathrm{CO}_{2}$-TPD profiles of AlPC and $x$ wt. \%Li/AlPC $(x=10,20$, and 30 wt. \%) catalysts.

AlPC clay is indeed a Brønsted acidic material, but it was modified to become basic alkali treatment by using an alkali cation-containing solution, $\mathrm{LiOH}$ in this study. The acidic strength also depends on the size and charge of the metal cations. The basicity of the AlPC surface is assumed to be the oxygen atoms' surface that interacts with a proton. It is expected that the surrounding framework of oxygen is known as Lewis basicity due to an adverse change of oxygen atoms in adjacent exchangeable cations. Hence, the primary step behind the heterogeneous catalytic reaction is to transfer the proton or the generation of the heteropolar donor-acceptor pair, as well as the catalyst efficiency based on acidic and basic properties of the heterogeneous catalyst surface. It can be concluded from these results that acidity and basicity of AlPC varied according to the Li loading. Secondly, acidity was found to be inversely proportional to the basicity.

\subsection{Microwave-Assisted Glycerol Polymerization}

The polyglycerol is primarily di-, tri- and tetraglycerol and some longer-chain heptaglycerol. The glycerol polymerization reaction to convert the glycerol to polyglycerol involves the removal of water molecules. The diglycerol and triglycerol (low-molecular-weight oligomers) were the two predominant components discussed in this study, owing to their extensive applications as fuel additives, emulsifiers, solvents, etc. Furthermore, no solvent was involved to minimize the complicity in separating catalyst when organic solvent and homogeneous catalysts were used, which affected the process economy and product purity. Four parameters involved in catalytic evaluation via microwave-assisted glycerol polymerization were Li loadings on AlPC (10, 20, $30 \mathrm{wt}$. \%), catalyst loadings $\left(2,3,4 \mathrm{wt}\right.$. \%), reaction temperature $\left(200,220,240^{\circ} \mathrm{C}\right)$ and reaction time $(1-4 \mathrm{~h})$. All the data points collected were taken in quadruplicates, and the average values were taken.

\subsubsection{Effect of Li Loadings on AIPC}

The effect of Li loadings (10, 20 and 30 wt. \%) on AlPC catalysts over the glycerol conversion, polyglycerol (particularly diglycerol and triglycerol) yields via microwave-assisted glycerol polymerization reaction at $200{ }^{\circ} \mathrm{C}$ within $4 \mathrm{~h}$ time-on-stream (TOS) are presented in Figure 7 . The unmodified AlPC was inactive with less than $10 \%$ of glycerol conversion, and polyglycerol yield can be observed within $4 \mathrm{~h}$ TOS (not shown). After AlPC was loaded with Li, significant improvements were demonstrated where the catalytic activities of Li/AlPC catalysts increased with increase in time-on-stream. This phenomenon manifested the crucial role played by $\mathrm{LiOH}$ in serving 
as an active metal, physicochemical properties modifier and basic sites increaser. The overall catalytic performance was observed in the following order under microwave irradiation as a heating source: 20 wt. \%Li/AlPC > 30 wt. \%Li/AlPC > 10 wt. \%Li/AlPC > AlPC. The maximum glycerol conversion of $70 \%$ was attained after $4 \mathrm{~h}$ of polymerization reaction with $63.9 \%$ polyglycerol yield of $58 \%$ at $200{ }^{\circ} \mathrm{C}$ in the presence of $10 \mathrm{wt}$. \%Li/AlPC catalyst. As metal loading increased to $20 \mathrm{wt}$. \% on pillared clay, the glycerol conversion reached up to $85.3 \%$ with polyglycerol yield of $78.5 \%$. However, a further increase in Li loading to $30 \mathrm{wt}$. \% resulted in a negative outcome, where there was a significant decrease in the short-chain polyglycerol yield after $2.5 \mathrm{~h}$ TOS (from $75 \%$ to $58.5 \%$ ) even though the glycerol conversion was as high as $89 \%$ at $4 \mathrm{~h}$. These results imply the occurrence of further polymerization of the short-chain polyglycerol into longer-chain polyglycerol.
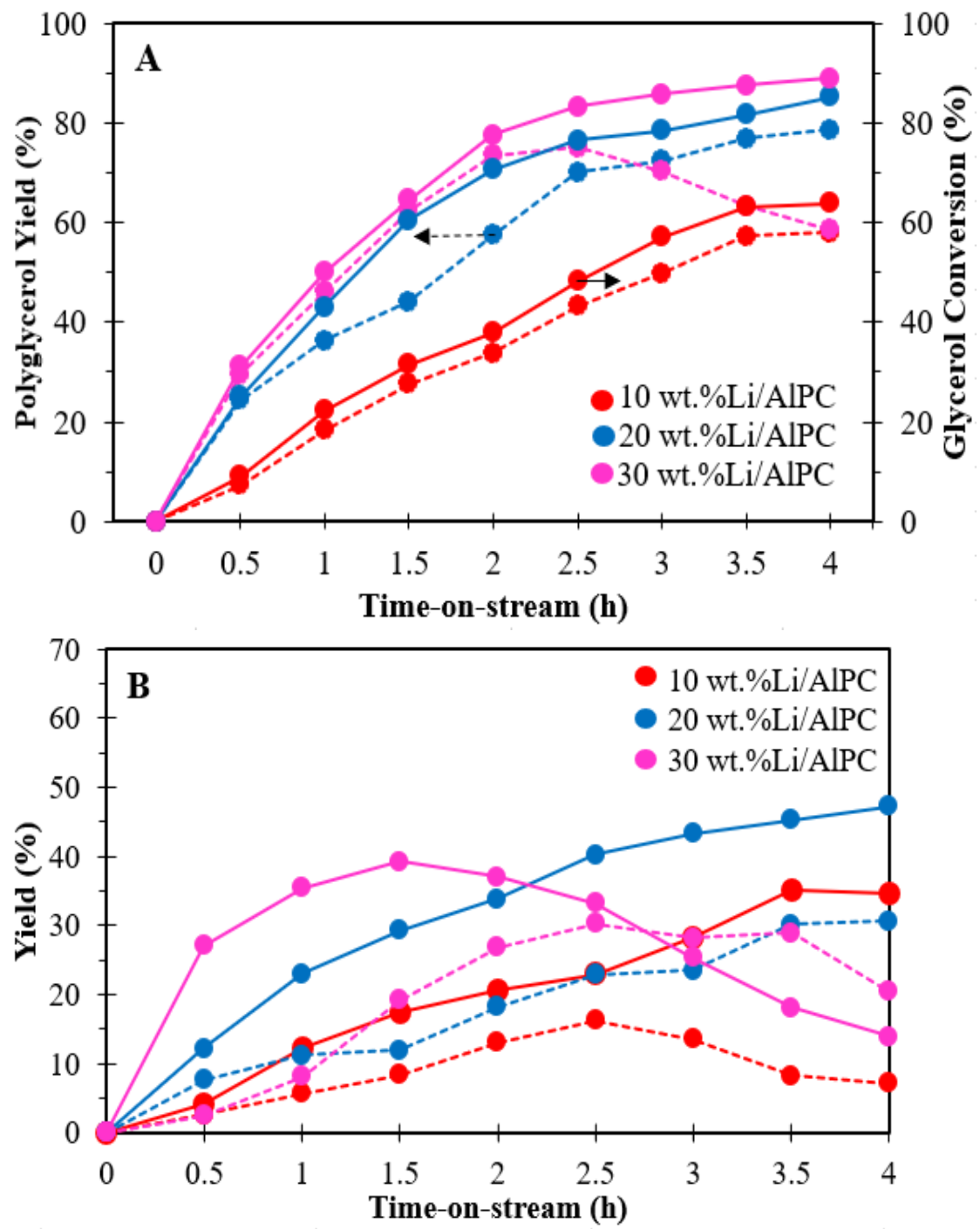

Figure 7. (A) Conversion of glycerol to polyglycerol and (B) short-chain oligomers (solid line: diglycerol, dotted line: triglycerol) formation in the presence of $2 \mathrm{wt}$. \% catalyst at $200{ }^{\circ} \mathrm{C}$.

From Figure 7B, the diglycerol was observed to increase within $4 \mathrm{~h}$ TOS for $10 \mathrm{wt}$. \%Li/AlPC, and the triglycerol yield increased at the first $2.5 \mathrm{~h}$ TOS until its highest point $(16.27 \%)$ but decreased to $7.2 \%$. For the case of $20 \mathrm{wt}$. \%Li/AlPC, both the diglycerol and triglycerol yield increased gradually with TOS to achieve $47.26 \%$ and $30.71 \%$, respectively. However, the maximum 39.25\% diglycerol yield was obtained at $1.5 \mathrm{~h}$ TOS for $30 \mathrm{wt}$. \%Li/AlPC, then gradually decreased to $14 \%$ at $4 \mathrm{~h}$ TOS. The same goes for triglycerol yield, which also decreased after $3.5 \mathrm{~h}$ TOS. From Table 3 , the 
longer-chain polyglycerol was formed at $16 \%$ and $24 \%$ for $10 \mathrm{wt}$. \%Li/AlPC and $30 \mathrm{wt}$. \%Li/AlPC, respectively, at $4 \mathrm{~h}$ TOS, which explains the drop in diglycerol and triglycerol yields as they have been further polymerized into longer-chain polyglycerol. Among them, the least long-chain polyglycerol was shown by $20 \mathrm{wt}$. \%Li/AlPC catalyst, evidencing its high selectivity to form the desired product, short-chain polyglycerol.

Table 3. Long-chain polyglycerol yields for different reaction conditions.

\begin{tabular}{cccccccccc}
\hline $\begin{array}{c}\text { Time } \\
\text { (h) }\end{array}$ & \multicolumn{3}{c}{ Li Loadings (wt. \%) } & $\boldsymbol{c}$ & \multicolumn{3}{c}{ Metal Loadings (wt. \%) } & \multicolumn{3}{c}{ Temperature $\left.^{\circ}{ }^{\circ} \mathbf{C}\right)^{c}$} \\
\cline { 2 - 10 } & $\mathbf{1 0}$ & $\mathbf{2 0}$ & $\mathbf{3 0}$ & $\mathbf{2}$ & $\mathbf{3}$ & $\mathbf{4}$ & $\mathbf{2 0 0}$ & $\mathbf{2 2 0}$ & $\mathbf{2 4 0}$ \\
\hline 0 & 0 & 0 & 0 & 0 & 0 & 0 & 0 & 0 & 0 \\
0.5 & 0.32 & 4.52 & 0 & 4.52 & 2.66 & 2.62 & 2.66 & 1.50 & 3.10 \\
1.0 & 0.36 & 2.04 & 2.45 & 2.04 & 3.00 & 4.71 & 3.00 & 3.00 & 10.71 \\
1.5 & 1.65 & 2.78 & 3.97 & 2.78 & 1.00 & 7.62 & 1.00 & 5.00 & 19.94 \\
2.0 & 0.1 & 5.25 & 9.55 & 5.25 & 0.25 & 11.56 & 0.25 & 2.25 & 23.76 \\
2.5 & 4.00 & 6.85 & 11.52 & 6.85 & 3.73 & 17.39 & 3.73 & 4.73 & 23.55 \\
3.0 & 8.00 & 5.61 & 16.72 & 5.61 & 2.61 & 17.36 & 2.61 & 5.61 & 22.27 \\
3.5 & 13.69 & 1.45 & 16.34 & 1.45 & 1.45 & 14.73 & 1.45 & 3.45 & 18.47 \\
4.0 & 16.054 & 0.57 & 24.02 & 0.57 & 0.57 & 22.46 & 0.57 & 0.57 & 17.20 \\
\hline
\end{tabular}

${ }^{a}$ Catalyst loading $=2 \mathrm{wt} . \%$, reaction temperature $=200^{\circ} \mathrm{C} .{ }^{b} \mathrm{Li}$ loading $=20 \mathrm{wt} . \%$, reaction temperature $=200{ }^{\circ} \mathrm{C}$.

${ }^{c} \mathrm{Li}$ loading $=20 \mathrm{wt}$. $\%$, catalyst loading $=3 \mathrm{wt}$. $\%$.

These findings evidenced that the glycerol polymerization is a base-catalyzed process in the current study. In general, the reaction can be divided into acid- or base-catalyzed reactions, but the former one is not preferred as it promotes a higher degree of oligomerization to yield polyglycerol with secondary products and thereby results in a decrease in the product quality [34]. The -OH groups of the glycerol molecule are Lewis base (electron donor groups), where these groups react rapidly with the -OH ions of the AlPC catalyst and then protonate it. For the next step, the alkoxy anion formed attacks the -OH group of another glycerol molecule to remove ann $\mathrm{H}_{2} \mathrm{O}$ molecule and form a polyglycerol product [35]. Glycerol conversion was augmented with the increase in the polarizing ability of the cations. It is hard to elucidate the mechanism without the participation of the Lewis and Bronsted acid sites, which has a significant role in glycerol polymerization. The role of metals ions and edges or defects have been tentatively hypothesized, which enable the -OH-leaving process in catalyzed glycerol polymerization into polyglycerol.

The poorest performance by the parent AlPC can be explained by the fact that unmodified AlPC is indeed a layered clay with basal spacing larger than the glycerol molecule. However, the LiOH-modified AIPC catalysts were able to tune their basal spacing for products yield and sustained their layer structure. In this case, the formation of a longer-chain molecule was restricted due to basal spacing limitation. The superiority of $20 \mathrm{wt}$. \% Li/AlPC as compared to other catalysts can be attributed to its pore size and basal spacing, with the proper equilibrium of Lewis acidity and basicity [34], that favoured the yield of desired products. This catalyst not only exhibited moderate basicity $(34.48 \mathrm{mmol} / \mathrm{g})$ but also formed suitable basal spacing $(21 \dot{\mathrm{A}})$ for efficient diglycerol and triglycerol yields as a result of the promising $\mathrm{LiOH}$ loadings. The poor products yield by $30 \mathrm{wt}$. \% Li/AlPC was due to its unfavourable properties; its excessive basicity $(45.48 \mathrm{mmol} / \mathrm{g})$ resulted in porosity deterioration and active alkaline cations leaching in the hot glycerol under heating [36]. The exposure to a higher basic solution concentration (30 wt. \%) could probably weaken the AlPC layered structure as well. The porosity and structural deterioration as a result of metal agglomeration also resulted in poor glycerol accessibility to the active sites of $30 \mathrm{wt}$. \%Li/AlPC. The condition worsened when the glycerol diffusion was blocked by the bigger-sized product molecules (mono-, di-, tri- tert-, butyl glycerol ethers) to diffuse out of the aperture of catalyst. The optimal Li loading for AlPC was $20 \mathrm{wt}$. \% for the preliminary screening test; therefore, this catalyst has further proceeded for subsequent testing. 


\subsubsection{Effect of Catalyst Loading}

The glycerol conversion and products yield with respect to reaction time at $200{ }^{\circ} \mathrm{C}$ over $20 \mathrm{wt}$. \%Li/AlPC catalyst at various catalyst loadings (2, 3 and $4 \mathrm{wt} . \%)$ are shown in Figure 8. The catalyst loading was computed with respect to the weight of the limiting reactant, glycerol. As observed in Figure $8 \mathrm{~A}, \mathrm{~B}$, the reaction profiles were different when varying catalyst loading. The glycerol conversion $(85.3 \%)$ and polyglycerol yield $(78.54 \%)$ were found to be lowest at the lowest catalyst concentration ( 2 wt. \%). The glycerol conversion of $92.25 \%$ was achieved with $83.54 \%$ polyglycerol yield for $3 \mathrm{wt}$. \% of catalyst. Both the diglycerol and triglycerol yields increased with TOS for both 2 and $3 \mathrm{wt}$. \% catalyst loading, and the overall yields were higher for $3 \mathrm{wt}$. \% catalyst loading. The highest diglycerol and triglycerol yields were marked at $52.26 \%$ and $33.5 \%$, respectively. Even though the glycerol conversion attained 95.1\% when it increased the catalyst loading from 3 to $4 \mathrm{wt}$. \%, its polyglycerol yield was unsatisfactory when drastic decrement (to $62.1 \%$ at $4 \mathrm{~h}$ TOS) was notified after the maximum point was achieved at $2.5 \mathrm{~h}$ TOS (73.6\%). As time increased, the diglycerol yield increased up to $2 \mathrm{~h}$ TOS but decreased to $21.5 \%$ for $4 \mathrm{wt}$. \% catalyst with a prolonged reaction time. Even though the triglycerol yield increased with reaction time for the first $3.5 \mathrm{~h}$ TOS with a maximum at $27.45 \%$, it decreased to $18.16 \%$ in the end. As tabulated in Table 3, the long-chain polyglycerol was more prone to produce when using $4 \mathrm{wt}$. \%Li/AlPC catalyst, which also explains the decline in the formation of the short-chain oligomers.
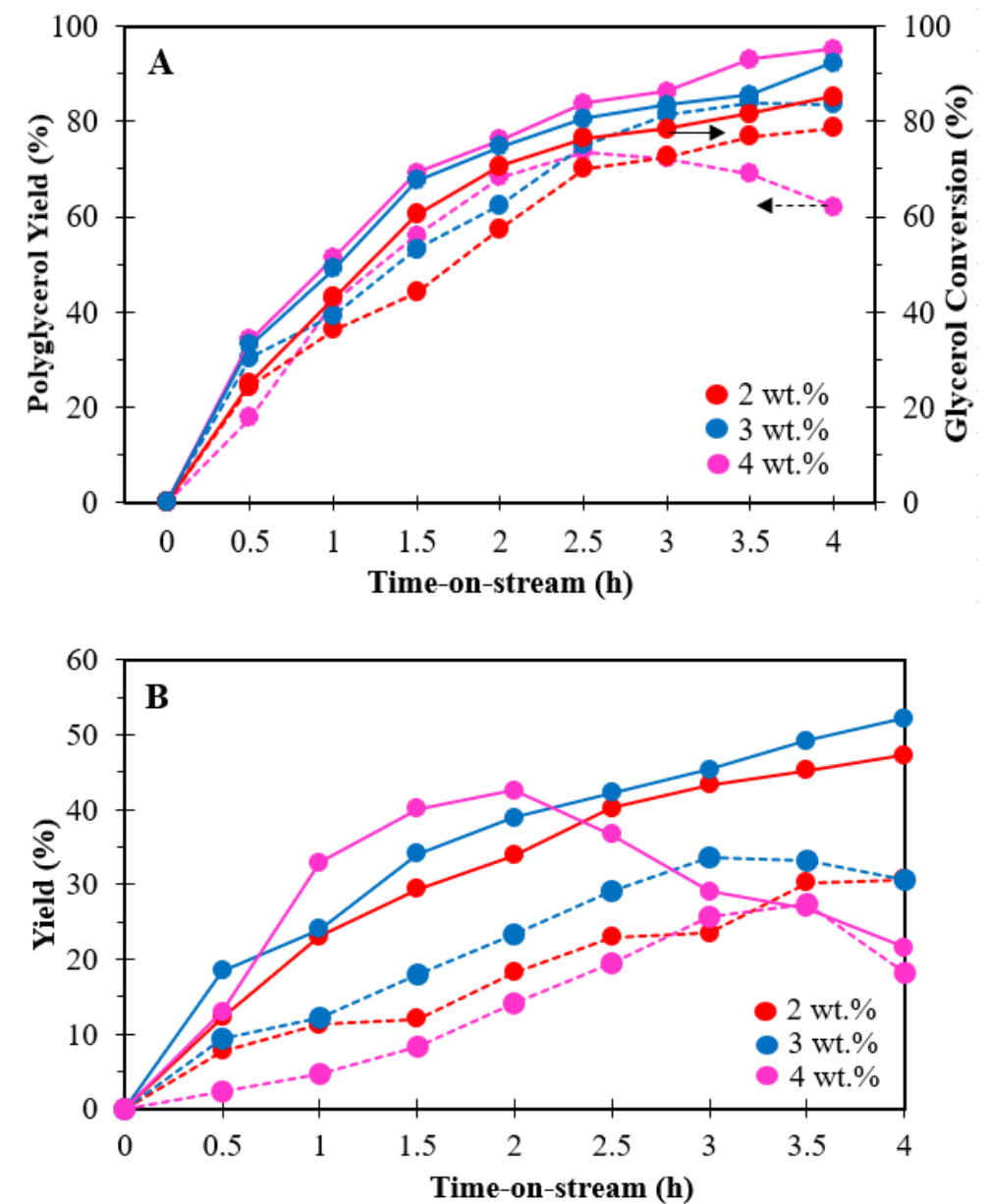

Figure 8. (A) Conversion of glycerol to polyglycerol and (B) short-chain oligomers (solid line: Diglycerol, dotted line: Triglycerol) formation in the presence of different catalyst wt. \% loading at $200{ }^{\circ} \mathrm{C}$.

These results proved that $3 \mathrm{wt}$. \% catalyst loading was the optimal point for this study. This is owing to the sufficient effective interaction amid the reactant molecules to form polyglycerol in the end, 
which was largely attributed to the adequate number of accessible active sites of the catalyst. After $2.5 \mathrm{~h}$ TOS, an increase in catalyst loading resulted in a non-accelerated reaction rate due to the mass transfer limit. Therefore, increasing the catalyst concentration to more than $3 \mathrm{wt}$. \% was not recommended because no significant improvement was observed, but it decreased the polyglycerol yield. Apart from promoting the over-polymerization reaction, a further increase of the catalyst loading to $3 \mathrm{wt}$. \% at the reaction conditions could also form glycerol back from back-scission of diglycerol, which was proven in a drastic decrease in the diglycerol and triglycerol yield with respect to time. As $3 \mathrm{wt} \%$ of $\mathrm{LiOH}$ catalyst performed the best during the reactions, this loading was chosen for the following research work.

\subsubsection{Effect of Reaction Temperature}

Glycerol polymerization is a temperature-dependent reaction, which is strongly influenced by the reaction temperature. The effect of reaction temperature $\left(200{ }^{\circ} \mathrm{C}, 220^{\circ} \mathrm{C}\right.$ and $\left.240{ }^{\circ} \mathrm{C}\right)$ on the polymerization was investigated over $3 \mathrm{wt}$. \% loading of $20 \mathrm{wt}$. \%Li/AlPC catalyst. Figure 9A,B shows the results of the current study for glycerol conversion and di/triglycerol yields. The glycerol conversion increased with the reaction temperature increment from $200^{\circ} \mathrm{C}$ to $220^{\circ} \mathrm{C}$. In comparison, the catalyst exhibited the least glycerol conversion and polyglycerol yield at a reaction temperature of $200{ }^{\circ} \mathrm{C}$. Glycerol conversion of $99.3 \%$ was obtained with $92.54 \%$ of polyglycerol yield for catalyst at $220^{\circ} \mathrm{C}$ as shown in Figure 9A. Both the diglycerol and triglycerol yields at $220^{\circ} \mathrm{C}$ surpassed the reaction performed at $200^{\circ} \mathrm{C}$, with the maximum diglycerol and triglycerol yield marked at $57.26 \%$ and $34.71 \%$, respectively. As the temperature increased to $240{ }^{\circ} \mathrm{C}$, glycerol conversion was $98 \%$, and the polyglycerol yield increased gradually until $2 \mathrm{~h}$ TOS and then decreased to $56.9 \%$ at $4 \mathrm{~h}$ TOS. For this reaction temperature, the diglycerol and triglycerol yield reached their maximum at $1.5 \mathrm{~h}$ and $3.5 \mathrm{~h}$, respectively, but decreased after that. The diglycerol and triglycerol yields were $21.5 \%$ and $18.16 \%$ after $4 \mathrm{~h}$ of the reaction at $240{ }^{\circ} \mathrm{C}$. Despite the glycerol conversion being very high at $240{ }^{\circ} \mathrm{C}$, the decreased polyglycerol yield suggested the further polymerization of short-chain polyglycerol to longer-chain oligomers. This statement was proven when the overall long-chain polyglycerol composition was the highest within $4 \mathrm{~h}$ TOS as tabulated in Table 3. This observation suggested that higher reaction temperature sped up the remaining glycerol and successive polymerization of diglycerol and triglycerol to longer-chain polyglycerol.

At high reaction temperature $\left(>300^{\circ} \mathrm{C}\right)$, active phase leaching into the reaction medium and the acrolein formation are the two main disadvantages of heterogeneous catalysts. Therefore, the reactions were conducted at the low reaction temperature to prevent substantial degradation reactions over the reactants, intermediates and products. However, relatively high temperature favours a high extent of product yield for an endothermic reaction; therefore, choosing optimal temperature is vital for maximum reactant conversion and product yield. The poorer catalytic performance was at $200{ }^{\circ} \mathrm{C}$ as the temperature was insufficient to overcome the activation energy required for successful glycerol conversion as the energy possessed by the glycerol molecule itself is weaker. It can be noted that polymerization is not favoured at $240{ }^{\circ} \mathrm{C}$ as secondary products tended to form secondary products instead of primary products (di- and triglycerol), due to the further activated reaction for further oligomerization to form long-chain polyglycerol. Therefore, $220^{\circ} \mathrm{C}$ was suggested as the optimal reaction temperature by considering the glycerol conversion and short-chain polyglycerol yield over $20 \mathrm{wt} \% \mathrm{Li} / \mathrm{AlPC}$-catalyzed microwave-assisted glycerol polymerization. This reaction temperature allows the optimal reaction rate to allow diffusion out of di- and triglycerol from the pores for new glycerol to polymerize. 

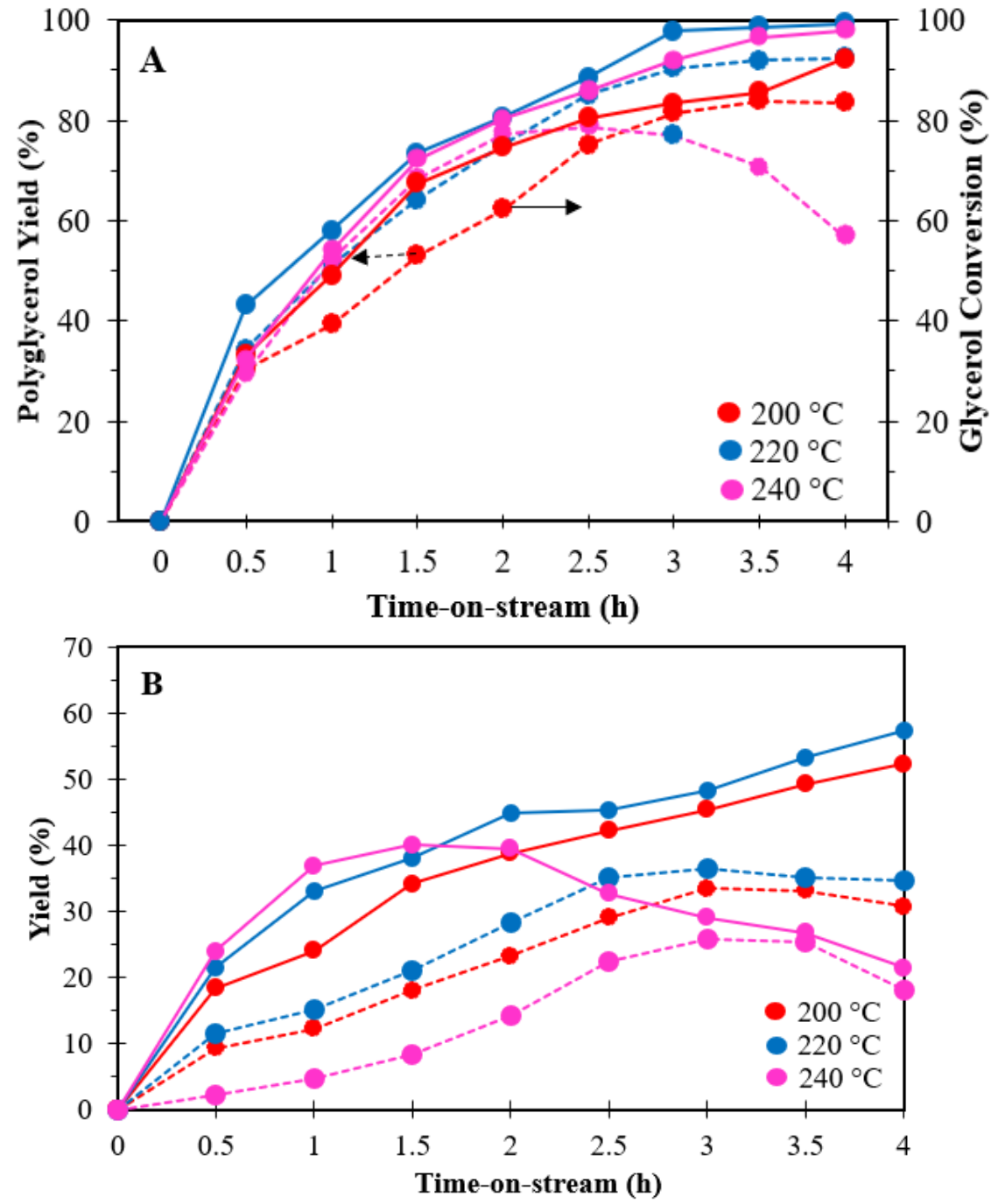

Figure 9. (A) Conversion of glycerol to polyglycerol and (B) short-chain oligimers (solid line: diglycerol, dotted line: triglycerol) formation in the presence of $2 \mathrm{wt}$. \% of $20 \mathrm{wt}$. \%Li/AlPC.

\subsubsection{Effect of Reaction Time}

The effect of reaction time on glycerol polymerization was performed on 3 wt. \% of $20 \mathrm{wt}$. \%Li/AlPC catalyst at $220^{\circ} \mathrm{C}$ as illustrated in Figures 7-9. By referring to the figures, the conversions and polyglycerol yields were mostly increased with TOS. This tendency of conversion and yield increase can be attributed to the impurities removal at prolonged reaction time. Generally, glycerol polymerization or glycerol oligomerization is a chain reaction in which glycerol forms diglycerol first, then triglycerol and so on to longer-chain polyglycerol. The short-chain oligomers polyglycerol are formed through successive glycerol polymerization where glycerol molecules condensed either in linear, cyclic or branched fashions [18]. Indeed, the diglycerol formed during the catalytic reaction might be transformed into higher polyglycerol under uncontrolled reaction condition or prolonged reaction time. The further polymerization steps after di- and triglycerol formation stop when the catalysts pore is not big enough. However, the short-chain polyglycerol may further continue its formation when the pore is sufficient to fit longer-chain polyglycerol. As observed in Figure 7A and Table 2, it was suggested that the pore sizes of $30 \mathrm{wt} . \% \mathrm{Li} / \mathrm{AlPC}$ were large enough to fit longer-chain polyglycerol when a drastic decrement in the polyglycerol was observed. In this study, the possible formation of higher cyclic oligomers that takes place at longer reaction time was minimized as reaction time up to $4 \mathrm{~h}$ only. Furthermore, the longer reaction time was susceptible to acrolein by-product 
generation due to double dehydration [37]. After the optimum reaction condition was confirmed at $20 \mathrm{wt}$ \% \% loading, $2 \mathrm{wt}$. \% catalyst loading, the glycerol conversion and polyglycerol yield were at a plateau after $3 \mathrm{~h}$. A further increase in reaction time to $4 \mathrm{~h}$ did not give any significant changes. Furthermore, the di- and triglycerol yields also showed minor increment only, signifying that the reaction might finish in the first $3 \mathrm{~h}$. Therefore, reaction time $3 \mathrm{~h}$ was chosen as the optimal point for this study.

The LiOH-impregnated AlPC catalyst facilitated via microwave technology proved to be more efficient for the glycerol polymerization into polyglycerol as compared to the previous studies. Furthermore, the desired reaction time was shorter for the synthesis of short-chain polyglycerol facilitated by microwave ( $3 \mathrm{~h}$ ) than the conventional heating method (12 h) [19] when using Li/AlPC. Most of the previously published work for the generation of selective polyglycerol was carried out by the conventional heating method, and typical reaction time for glycerol polymerization was more than $8 \mathrm{~h}$. To conclude, these results confirmed the significant advantages derived from microwave heating to achieve a maximum $99.3 \%$ glycerol conversion and $92.5 \%$ polyglycerol yield, as the required heating time in previously published work was approximately $12 \mathrm{~h}$ by the conventional heating method. Hence, microwave technology is highly feasible to be adopted for polymerization reaction for maximum glycerol conversion and short-chain polyglycerol formation.

\subsection{Spent Catalyst Characterization}

The TGA graph of spent AlPC and $x$ wt. \%Li/AlPC ( $x=10,20$ and $30 \mathrm{wt}$. \%) catalysts at catalyst loading $=2 \mathrm{wt} . \%$ and reaction temperature $=200{ }^{\circ} \mathrm{C}$ is shown in Figure 10. Overall, the weight loss of all the spent catalysts can be considered small, which is less than $25 \%$. There is a certain indication for each weight loss at different temperature regions. Weight loss at the $70-160^{\circ} \mathrm{C}$ range is assigned to the adsorbed water molecules elimination, whilst the temperature between $160-270{ }^{\circ} \mathrm{C}$ can be assigned to the elimination of residual adsorbed glycerol monomers. At a temperature more than $270{ }^{\circ} \mathrm{C}$, it might correspond to the thermal degradation of the catalyst itself. The removal of dehydroxylation and physisorbed caused by the breaking of structural hydroxyl groups of the AlPC support took place at a temperature of more than $500{ }^{\circ} \mathrm{C}$ [18]. The weight loss of the spent catalysts followed the order of AlPC $>10$ wt. \%Li/AlPC $>30$ wt. \%Li/AlPC $>20$ wt. \%Li/AlPC. Therefore, there is no doubt that the $20 \mathrm{wt} . \% \mathrm{Li} / \mathrm{AlPC}$ was selected as the best catalyst in this study.

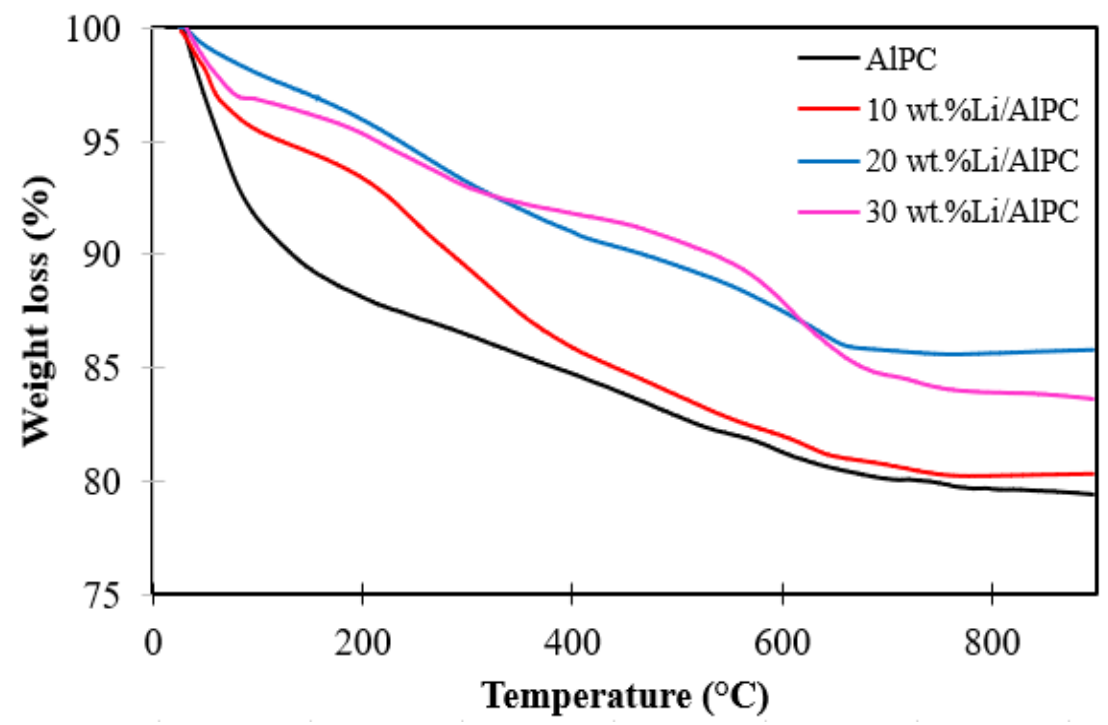

Figure 10. Thermal gravimetric analysis (TGA) graph of spent AlPC and $x$ wt. \%Li/AlPC ( $x=10$, 20 and $30 \mathrm{wt}$. \%) catalysts at catalyst loading $=2 \mathrm{wt} . \%$, reaction temperature $=200{ }^{\circ} \mathrm{C}$. 


\section{Conclusions}

In this study, microwave-assisted catalytic polymerization has been studied using LiOH-modified AlPC catalyst for the conversion of glycerol into short-chain polyglycerol (di- and triglycerol). $\mathrm{LiOH}$ was able to tune the pristine basal spacing of AlPC catalysts for their products yields and sustain their layer structure. From the results obtained, $20 \mathrm{wt}$. \% Li/AlPC was proven to perform the best selective polymerization as compared to $10 \mathrm{wt}$. \% and $30 \mathrm{wt}$. \% Li/AlPC. The superiority of $20 \mathrm{wt} . \%$ $\mathrm{Li} /$ AlPC catalysts can be credited to its high surface area $\left(95.48 \mathrm{~m}^{2} / \mathrm{g}\right)$, moderate pore size $(19.21 \mathrm{~nm})$, interlayer space $(21 \dot{A})$, with the proper equilibrium of Lewis acidity $(2.35 \mathrm{mmol} / \mathrm{g})$, and basicity $(34.48 \mathrm{mmol} / \mathrm{g})$. These attributes indicate an adequate number of accessible actives sites of the catalyst for sufficient effective interaction between the reactant molecules. The poor catalytic performance by $30 \mathrm{wt}$. \%Li/AlPC was due to its excessive basicity $(45.48 \mathrm{mmol} / \mathrm{g})$ and metal agglomeration that resulted in porosity deterioration and active alkaline cations leaching. An excellent glycerol conversion of $99.3 \%$ with the overall polyglycerol yield of $92.5 \%$ was achieved at catalyst loading $=3 \mathrm{wt} . \%$, reaction temperature $=220^{\circ} \mathrm{C}$ and reaction time $=3 \mathrm{~h}$ in the presence of $20 \mathrm{wt}$. \%Li/AlPC catalyst. The catalyst produced the prime yield of target oligomers of di- and tri-glycerol at $57.26 \%$ and $34.71 \%$, respectively. Too low temperature is not favourable to overcome the activation energy required for successful glycerol conversion, while too high temperature led to the formation of secondary products by the further polymerization reaction. Further increase of the reaction time to $4 \mathrm{~h}$ did not show a positive impact due to the completion of the reaction in the first $3 \mathrm{~h}$. Furthermore, the desired reaction time was shorter when facilitated by microwave $(3 \mathrm{~h})$ than the conventional heating method (more than $8 \mathrm{~h}$ ). Twenty wt. \%Li/AlPC catalyst was verified to be a highly active and efficient catalyst for glycerol polymerization to value-added short-chain polyglycerol production via microwave irradiation as a heating source.

Author Contributions: Conceptualization, M.S. and M.A.; data curation, M.S.; B.A.; M.R. and M.A.; formal analysis, S.Y., M.A.; R.B.; M.S. and A.A.; funding acquisition, M.A.; investigation, M.S.; methodology, M.S.; Project administration, M.A.; resources, M.A., R.B. and A.A.; supervision, M.A., B.A., R.S. and M.A.; writing-original draft, M.S.; writing-review and editing, S.Y., B.A., R.B. and C.C.C. All authors have read and agreed to the published version of the manuscript'.

Funding: This research is funded by Universiti Teknologi PETRONAS under YUTP grant (0153LCO-144).

Acknowledgments: The authors sincerely acknowledge the financial support provided by Universiti Teknologi PETRONAS under YUTP grant (0153LCO-144). Support from the Ministry of Education Malaysia through HiCOE award to CBBR is duly acknowledged.

Conflicts of Interest: The authors declare no conflict of interest.

\section{References}

1. Martin, A.; Richter, M. Oligomerization of glycerol-A critical review. Eur. J. Lipid Sci. Technol. 2010, 113, 100-117. [CrossRef]

2. Tan, H.; Aziz, A.A.; Aroua, M. Glycerol production and its applications as a raw material: A review. Renew. Sustain. Energy Rev. 2013, 27, 118-127. [CrossRef]

3. Liu, X.; Ma, H.; Wu, Y.; Wang, C.; Yang, M.; Yan, P.; Welz-Biermann, U. Esterification of glycerol with acetic acid using double $\mathrm{SO} 3 \mathrm{H}-$ functionalized ionic liquids as recoverable catalysts. Green Chem. 2011, 13, 697. [CrossRef]

4. Sun, D.; Yamada, Y.; Sato, S.; Ueda, W. Glycerol hydrogenolysis into useful C3 chemicals. Appl. Catal. B 2016, 193, 75-92. [CrossRef]

5. Katryniok, B.; Paul, S.; Bellière-Baca, V.; Rey, P.; Dumeignil, F. Glycerol dehydration to acrolein in the context of new uses of glycerol. Green Chem. 2010, 12, 2079. [CrossRef]

6. Talebian-Kiakalaieh, A.; Amin, N.A.S.; Najaafi, N.; Tarighi, S. A Review on the Catalytic Acetalization of Bio-renewable Glycerol to Fuel Additives. Front. Chem. 2018, 6, 6. [CrossRef]

7. Ayoub, M.; Khayoon, M.; Abdullah, A.Z. Synthesis of oxygenated fuel additives via the solventless etherification of glycerol. Bioresour. Technol. 2012, 112, 308-312. [CrossRef] 
8. Melero, J.A.; Vicente, G.; Paniagua, M.; Morales, G.; Muñoz, P. Etherification of biodiesel-derived glycerol with ethanol for fuel formulation over sulfonic modified catalysts. Bioresour. Technol. 2012, 103, 142-151. [CrossRef]

9. Quispe, C.A.; Coronado, C.J.; De Carvalho, J.A. Glycerol: Production, consumption, prices, characterization and new trends in combustion. Renew. Sustain. Energy Rev. 2013, 27, 475-493. [CrossRef]

10. Chong, C.C.; Aqsha, A.; Ayoub, M.; Sajid, M.; Abdullah, A.Z.; Yusup, S.; Abdullah, B. A review over the role of catalysts for selective short-chain polyglycerol production from biodiesel derived waste glycerol. Environ. Technol. Innov. 2020, 19, 100859. [CrossRef]

11. Gholami, Z.; Abdullah, A.Z.; Lee, K.T. Heterogeneously catalyzed etherification of glycerol to diglycerol over calcium-lanthanum oxide supported on MCM-41: A heterogeneous basic catalyst. Appl. Catal. A Gen. 2014, 479, 76-86. [CrossRef]

12. Ayoub, M.; Abdullah, A.Z. Instability of SBA-15 to Strong Base: Effects of LiOH Impregnation on its Surface Characteristics and Mesoporous Structure. J. Appl. Sci. 2011, 11, 3510-3514. [CrossRef]

13. Jerome, F.; Pouilloux, Y.; Barrault, J. Rational Design of Solid Catalysts for the Selective Use of Glycerol as a Natural Organic Building Block. ChemSusChem. 2008, 1, 586-613. [CrossRef] [PubMed]

14. Gholami, Z.; Abdullah, A.Z.; Lee, K.T. Glycerol etherification to polyglycerols using $\mathrm{Ca}_{1+\mathrm{x}} \mathrm{Al}_{1-\mathrm{x}} \mathrm{La}_{\mathrm{x}} \mathrm{O}_{3}$ composite catalysts in a solventless medium. J. Taiwan Inst. Chem. Eng. 2013, 44, 117-122. [CrossRef]

15. Gonçalves, M.; Castro, C.S.; Oliveira, L.C.; Carvalho, W.A. Green acid catalyst obtained from industrial wastes for glycerol etherification. Fuel Process. Technol. 2015, 138, 695-703. [CrossRef]

16. Ayoub, M.; Sufian, S.; Hailegiorgis, S.M.; Ullah, S.; Uemura, Y. Conversion of glycerol to polyglycerol over waste duck-bones as a catalyst in solvent free etherification process. Iop Conf. Ser. Mater. Sci. Eng. 2017, 226, 012073. [CrossRef]

17. Gonçalves, M.; Soler, F.C.; Isoda, N.; Carvalho, W.A.; Mandelli, D.; Sepúlveda, J. Glycerol conversion into value-added products in presence of a green recyclable catalyst: Acid black carbon obtained from coffee ground wastes. J. Taiwan Inst. Chem. Eng. 2016, 60, 294-301. [CrossRef]

18. Ayoub, M.; Abdullah, A.Z. Diglycerol synthesis via solvent-free selective glycerol etherification process over lithium-modified clay catalyst. Chem. Eng. J. 2013, 225, 784-789. [CrossRef]

19. Ayoub, M.; Abdullah, A.Z. LiOH-modified montmorillonite K-10 as catalyst for selective glycerol etherification to diglycerol. Catal. Commun. 2013, 34, 22-25. [CrossRef]

20. Estevez, R.; Lopez-Pedrajas, S.; Luna, D.; Bautista, F. Microwave-assisted etherification of glycerol with tert-butyl alcohol over amorphous organosilica-aluminum phosphates. Appl. Catal. B 2017, 213, 42-52. [CrossRef]

21. Gil, A.; Gandía, L.M.; Vicente, M.A. Recent Advances in the Synthesis and Catalytic Applications of Pillared Clays. Catal. Rev. 2000, 42, 145-212. [CrossRef]

22. Chong, C.C.; Teh, L.P.; Setiabudi, H.D. Syngas production via CO2 reforming of $\mathrm{CH}_{4}$ over Ni-based SBA-15: Promotional effect of promoters (Ce, Mg, and Zr). Mater. Today Energy 2019, 12, 408-417. [CrossRef]

23. Mohapatra, P.; Mishra, T.; Parida, K. Pillared Clay as an Effective Catalyst for Low Temperature VOCs Decomposition. Key Eng. Mater. 2013, 571, 71-91. [CrossRef]

24. Soetaredjo, F.E.; Ayucitra, A.; Ismadji, S.; Maukar, A.L. KOH/bentonite catalysts for transesterification of palm oil to biodiesel. Appl. Clay Sci. 2011, 53, 341-346. [CrossRef]

25. Chong, C.C.; Setiabudi, H.D.; Jalil, A.A. Dendritic fibrous SBA-15 supported nickel (Ni/DFSBA-15): A sustainable catalyst for hydrogen production. Int. J. Hydrog. Energy 2019, 45, 18533-18548. [CrossRef]

26. Chong, C.; Bukhari, S.; Cheng, Y.; Setiabudi, H.D.; Jalil, A.; Phalakornkule, C. Robust Ni/Dendritic fibrous SBA-15 (Ni/DFSBA-15) for methane dry reforming: Effect of Ni loadings. Appl. Catal. A Gen. 2019, 584, 117174. [CrossRef]

27. Ayoub, M.; Inayat, A.; Hailegiorgis, S.M.; Bhat, A.H. Synthesis of alumina based alkaline catalyst for biodiesel-derived glycerol to polyglycerol. J. Adv. Mater. Res. 2016, 1133, 33-37. [CrossRef]

28. Guo, J.; Nguyen, B.N.; Li, L.; Meador, M.A.B.; Scheiman, D.A.; Cakmak, M. Clay reinforced polyimide/silica hybrid aerogel. J. Mater. Chem. A 2013, 1, 7211-7221. [CrossRef]

29. Krupskaya, V.V.; Zakusin, S.; Tyupina, E.A.; Dorzhieva, O.; Zhukhlistov, A.P.; Belousov, P.; Timofeeva, M.N. Experimental Study of Montmorillonite Structure and Transformation of Its Properties under Treatment with Inorganic Acid Solutions. Miner. 2017, 7, 49. [CrossRef] 
30. Priya, S.S.; Selvakannan, P.; Chary, K.V.R.; Kantam, M.L.; Bhargava, S.K. Solvent-free microwave-assisted synthesis of solketal from glycerol using transition metal ions promoted mordenite solid acid catalysts. Mol. Catal. 2017, 434, 184-193. [CrossRef]

31. Surendra, B.; Veerabhadraswamy, M. Microwave assisted synthesis of Schiff base via bioplatform chemical intermediate (HMF) derived from Jatropha deoiled seed cake catalyzed by modified Bentonite clay. Mater. Today Proc. 2017, 4, 11968-11976. [CrossRef]

32. Ayoub, M.; Ullah, S.; Inayat, A.; Mahmood, S.M. Investigation of Biodiesel-Drive Glycerol Conversion to Polyglycerol over Basic Modified ALPC Catalyst. ARPN J. Eng. Appl. Sci. 2016, 11, 2668-2672.

33. Bineesh, K.V.; Kim, D.-K.; Kim, M.-I.; Selvaraj, M.; Park, D.-W. Design, synthesis and characterization of vanadia-doped iron-oxide pillared montmorillonite clay for the selective catalyticoxidation of $\mathrm{H} 2 \mathrm{~S}$. Dalton Trans. 2011, 40, 3938-3945. [CrossRef] [PubMed]

34. Sivaiah, M.; Robles-Manuel, S.; Valange, S.; Barrault, J. Recent developments in acid and base-catalyzed etherification of glycerol to polyglycerols. Catal. Today 2012, 198, 305-313. [CrossRef]

35. Ruppert, A.M.; Meeldijk, J.D.; Kuipers, B.W.M.; Erné, B.H.; Weckhuysen, B.M. Glycerol Etherification over Highly Active CaO-Based Materials: New Mechanistic Aspects and Related Colloidal Particle Formation. Chem. Eur. J. 2008, 14, 2016-2024. [CrossRef]

36. Muhammad, A.F.S.; Awad, A.; Saidur, R.; Masiran, N.; Salam, A.; Abdullah, B. Recent advances in cleaner hydrogen productions via thermo-catalytic decomposition of methane: Admixture with hydrocarbon. Int. J. Hydrog. Energy 2018, 43, 18713-18734. [CrossRef]

37. Bookong, P.; Ruchirawat, S.; Boonyarattanakalin, S. Optimization of microwave-assisted etherification of glycerol to polyglycerols by sodium carbonate as catalyst. Chem. Eng. J. 2015, 275, 253-261. [CrossRef]

(C) 2020 by the authors. Licensee MDPI, Basel, Switzerland. This article is an open access article distributed under the terms and conditions of the Creative Commons Attribution (CC BY) license (http://creativecommons.org/licenses/by/4.0/). 